\title{
Body Status and Occupational Health Hazards of Female Workers :
}

\section{A Comparative Analysis}

\begin{abstract}
:
Objective: Health is nothing but a state of complete physical, mental and social wellbeing not merely the absence of disease. Health depends on life style and requires the promotion of healthy life style. Health is both a consequence of an individual's life style and factors in determining it. Working pattern or type of work has long been known to influence human health specially. The present study was under taken to evaluate the body status and physiological stress and occupational health hazards of the female workers. Methods: According to the work load the working group was classified in to low physical work group (LPWG) and the moderate type of physical work group (MPWG). Eighty women (forty in each group), excluding pregnant women, were selected from the municipal area of Bhilai, Chhattisgarh, India, aged between 20 to 40 years. The anthropometric measurement and skin fold thickness were taken, from which the body mass index (BMI) and fat percentage were determined. The blood pressure of all the subjects was taken by mercury sphygmomanometer at resting condition. The occupational health hazards were determined by questionnaire technique. Result: The result indicates that the MPWG workers suffer in significantly $(p<0.001)$ low weight, BMl and Fat\% than that of the LPWG workers. The MPWG workers also suffer from significantly $(p<0.001)$ higher percentage of musculoskeletal disorder (MSD) at neck, shoulder, elbow, wrist, finger, cuff and feet-ankle joint. MPWG workers, hemoglobin concentration also significantly $(p<0.01)$ lower than that of the LPWG workers. Conclusion: It may be concluded that, this study is helpful to identify the risk factor for the occurrence of different cardiovascular as well as musculoskeletal abnormalities and accordingly prevention program, regarding proper food habit be undertaken.
\end{abstract}

Key Words: Female workers; Fat percentage; Body mass index; Blood pressure

Dimpal Arora', Pooja Sitholay ${ }^{2}$ and Soudeep $\mathrm{Kr} \mathrm{Sau}^{3}$

1Department of Physiology, C.M. Medical College, Kachandur, Durg 2Department of Bio-Chemistry, C.M. Medical College, Kachandur, Durg

${ }^{3}$ Department of Physiology, Rungta College of Dental Sciences and Research, Kokha-Kurud Road, Bhilai

\section{Introduction}

Education Status affecting type of work and working pattern has long been known to influence health of standard of living, quality of life, family size and pattern of diseases in females. Subcutaneous fat is a simpler, quicker procedure to get an estimate of body fat percentages which is distributed quite differently in females, i.e., triceps skin fold, biceps skin fold, sub scapular skin fold, abdomen skin fold, thigh skin fold, and suprailliac skin fold gives the fat index (FI). Blood pressure is again an important parameter indicating the cardiovascular functioning of the body expressed as systolic pressure and diastolic pressure, i.e., $100 / 60 \mathrm{~mm}$ of $\mathrm{Hg}$ to $120 / 80 \mathrm{~mm}$ of $\mathrm{Hg}$ respectively. Blood pressure also varies with different factors like age, sex, body posture, sleep, emotional states of the individual etc. The WHO defined, hypertension in adults as a systolic pressure equal to or greater than $160 \mathrm{~mm}$ of $\mathrm{Hg}$ and /or a diastolic pressure equal to or greater then $95 \mathrm{~mm}$ of $\mathrm{Hg}$ [1]. In the present study skin fold thickness, blood pressure and the frequency of heart beat has been determined to assess the cardiovascular status of the female workers. The body composition may have an influence of the blood pressure, work pattern, racial and nutritional factors are also closely related to the blood pressure as well as to the different cardiovascular abnormalities.

In view of the problems in different occupations and working environments, World Health Organization had taken a Global Strategy on Occupational Health for All by the Year 2000 [2]. India has also included occupational and environmental health as area of concern in the tenth five-year plan (2002-2007) [3]. 
In recent times, emphasis is given primarily on sedentary occupations which may enhance the chances of cardiovascular diseases [4] Heavy manual labour too can cause low back pain $[5,6]$, injuries [7], musculoskeletal problems [8], and so forth, to the workers.

In a comparative study between body builders [9] and obese individuals [10] revealed that there was a close relation between blood pressure and body composition. Systolic blood pressure was similar while it was significantly higher in the control group. This confirmed the relationship between increased diastolic pressure and body fat excess; the finding of increased systolic blood pressure suggests caution in body building. Another study also shows the association between obesity, systolic and diastolic pressure established the relationship between obesity and systolic or diastolic blood pressure[11].

The main aim and objectives of the present study were to evaluate the body status and physiological stress and occupational health hazards of the female workers. And also an attempt has been taken to evaluate the relationship between the body status and physiological parameters of the working groups.

\section{Methods}

Selection of site and subject : The survey was made only on female workers. The subjects were selected randomly having the age range of 20-40 yrs. The workers were classified into two groups, viz., low physical work group (LPWG) and the moderate type of physical work group (MPWG). The number of workers in each group was 40 . The study has been conducted in different areas of Bhilai, Chhattisgarh, during the period 2013 -2014. For this study the office workers, teachers and students are considers as LPWG and the made servant and small scale factory workers are consider as MPWG.

Anthropometric Measurements : Different body dimensions of the workers were taken by means of anthropometer (Holtain), sliding caliper and steel tape by adopting proper landmark definition [12] and standard measuring techniques [13]. The body weight of the subject was measured by a portable weighing machine (Libra) with an accuracy of $0.5 \mathrm{~kg}$. The data recorded for a subject was the mean of three trials. All subjects were wearing light clothes and were bare footed during measurements.

For measuring the Mean abdominal circumference (Mabc) the subjects were asked to stand erect looking straight, heels together and weight distributed equally on both feet. The steel tape was held in a horizontal plane. The measurement was taken laterally at the level of the crest and anterior of umbilicus. Body Mass Index was calculated from the height and weight of the female subjects by the Johnson and Nelson formula [14]. The body composition of the subject was determined by measuring the skin-fold thickness. The triceps, suprailiac and thigh skin folds were taken. The skin fold caliper (Holtain) was used for these measurements. The measurements were taken under standardized condition and using proper landmarks [14, 15].
From the skin fold data, total weight of body fat and lean body weight was determined by the calculating the body density [16, 17] and percentage of body fat of female subjects [18]. The following formulae were used:

a) Body density (gm/cc) for women = $1.0994921-$ 0.0009929 (sum of triceps, suprailiac and thigh skin folds) + 0.0000023 (sum of the same three skin folds) ${ }^{2}-0.0001392$ (age in years).

b) Percentage of fat $=\{(4.95 \div$ Body density $)-4.50\} \times 100$

Measurement of Cardiovascular Parameters : The systolic and diastolic blood pressure was determined by auscultator's method with the help of a sphygmomanometer (mercury type). The measurements were taken in supine position after a rest period of 15 minutes. The subjects did not report any symptoms of hypertension or hypotension during the study. The resting pulse rate was taken as 30 beats time recording method.

Muscles Skeletal Disorder : To compare the musculoskeletal system, a questionnaire technique [19] was used. The questions include different problem related with their health depending on their work pattern. Questionnaire include whether there is any problem or not in different part of the body such as neck, shoulder, elbow, wrist, thighs, hips, knees \& foot or ankle etc. And after asking questions the percentage of problems were analyzed.

\section{General Health Status}

The hemoglobin $(\mathrm{Hb})$ percentage was measured according to Sahlis' method by using the hemoglobinometer. For this purpose the standard procedure [20] was followed for the determination of the haemoglobin percentage $(\mathrm{Hb} \%)$.

Some female related problems line menstrual problem, problems relating with pregnancy etc. were also asked to all silicate. So it gives us an idea about types of health problem among different work group.

Statistical analysis : All statistical analyses were performed using the STATISTICA software (version 6.0). Relationships between blood pressure and other parameters were analyzed by simple correlation. The mean and standard deviation was calculated for all data. Paired 't'-test and correlation (point biserial $r$ and product moment $r$ ) among different groups of parameters had also been made. Chi-square test was used for comparison of categorical variables. The values of $p<0.05$ were considered statistically significant.

\section{Results}

The different body dimension parameters including height, weight and mean abdominal circumference (Mabc) were calculated and their mean, standard deviation value and significance difference were presented in the Table-I. From the collected data the BMI, percentage of body fat (fat $\%$ ) and fat index $(\mathrm{FI})$ were calculated and those are also represented in the 
same table. From the result it may be noted that there was no such significant $(p<0.05)$ difference in mean height between LPWG workers and the MPWG workers. From the result it also noted that the mean body weight of the LPWG workers was significantly $(p<0.001)$ higher than that of the MPWG workers. The other parameters like body mass index (BMI), body surface area (BSA), percentage of fat(Fat \%), fat index (FI) and mean abdominal circumference (Mabc), also shows the high level of significant $(p<0.001)$ difference between the group.

Table I Mean and Standard Deviation (SD) of Height, Weight, Body Mass Index (BMI), Body surface area, Fat percentage, Fat index (FI) and Maximum Abdominal circumference (MABC) of workers.

\begin{tabular}{|c|c|c|}
\hline Parameters & $\begin{array}{l}\text { LPWG workers } \\
\text { (Mean } \pm \text { SD) }\end{array}$ & $\begin{array}{l}\text { MPWG workers } \\
\text { (Mean } \pm \text { SD) }\end{array}$ \\
\hline Height (Cms) & $147.625 \pm 12.86$ & $143.03 \pm 5.27^{* *}$ \\
\hline Weight (Kg) & $52.4 \pm 8.06$ & $40.15 \pm 5.63^{*}$ \\
\hline BMI & $24.32 \pm 4.005$ & $19.55 \pm 1.769^{*}$ \\
\hline BSA (Sq mt) & $1.43 \pm 0.158$ & $1.24 \pm 0.101^{*}$ \\
\hline Fat $\%$ & $15.34 \pm 2.957$ & $9.15 \pm 0.86^{*}$ \\
\hline $\mathrm{FI}(\mathrm{mm})$ & $63.82 \pm 13.77$ & $32.91 \pm 7.54^{*}$ \\
\hline $\operatorname{Mabc}(\mathrm{Cms})$ & $74.33 \pm 11.20$ & $65.91 \pm 5.541^{*}$ \\
\hline
\end{tabular}

The cardiovascular parameters i.e., pulse rate, systolic blood pressure (SBP) and diastolic blood pressure (DBP) are given in Table II. The result indicates that there was a significant $(p<0.001)$ difference in resting pulse rate and SBP $(p<0.01)$, but no such difference was found in DBP. From the study of the blood pressure the subjects were categorized into three different group, viz., hypotensive, normotensive and hypertensive according to the guidelines of WHO [21] and JNC-VI criteria [22]. The percentage distribution of those parameters are given in Figure 1. The figure indicates that the $95 \%$ of the female MPWG workers suffer in hypotensive blood pressure where as the 15\% of the female LPWG workers suffer in hypertensive blood pressure and $47 \%$ are suffer in hypotensive blood pressure.

Table II Table shows the Mean and Standard Deviation (SD) of Normal pulse rate (PR), Normal systoric blood pressure (SBP) and Diastolic blood pressure (DBP) of both group of workers.

\begin{tabular}{|c|c|c|}
\hline Parameters & $\begin{array}{l}\text { LPWG workers } \\
\text { (Mean } \pm \text { SD) }\end{array}$ & $\begin{array}{l}\text { MPWG workers } \\
\text { (Mean } \pm \text { SD) }\end{array}$ \\
\hline $\begin{array}{l}\text { Normal Pulse Rate } \\
\text { (b/min) }\end{array}$ & $78.95 \pm 6.85$ & $71.65 \pm 3.23^{*}$ \\
\hline $\begin{array}{l}\text { Normal Systolic Blood } \\
\text { Pressure }(\mathrm{mmHg})\end{array}$ & $107.1 \pm 7.19$ & $102.65 \pm 4.18^{\#}$ \\
\hline \multirow[t]{2}{*}{$\begin{array}{l}\text { Normal Diastolic Blood } \\
\text { Pressure }(\mathrm{mmHg})\end{array}$} & $78.05 \pm 5.66$ & $77.8 \pm 9.29$ \\
\hline & $* p<0.001$ & w.r.t. LPWG workers \\
\hline
\end{tabular}

Table-III shows correlation coefficient of FI with other parameters such as SBP, DBP, PR, BMI and MabC. The positive correlation
Fig 1. Percentage distribution of Hypertensive, Normal and Hypotensive blood pressure both Groups of workers

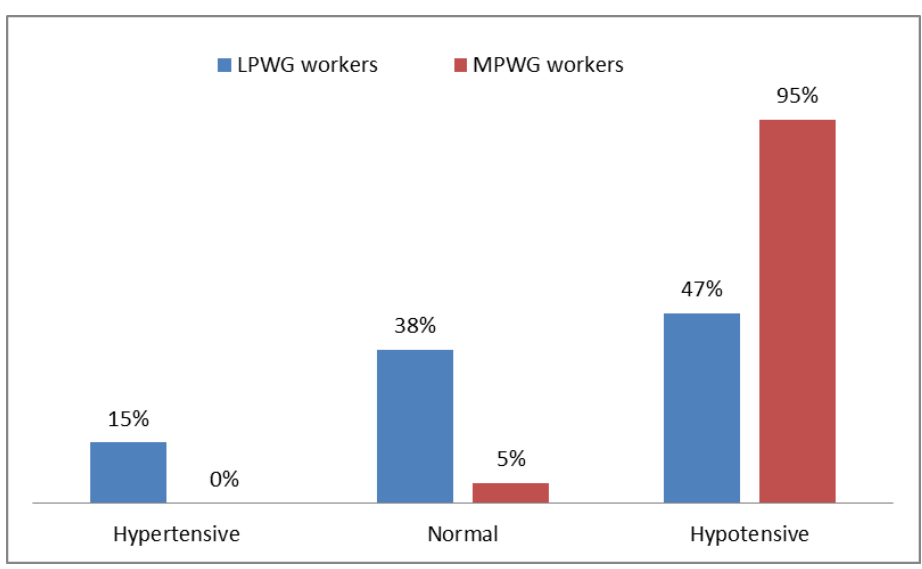

was found in SBP, DBP \& BMI in both the group but the level of ' $r$ ' value not so high in all cases except correlation of FI-SBP ( $r=$ 0.524) with LPWG workers. Whereas, the $\mathrm{FI}$ is negatively correlated with Pulse rate and Mabc in LPWG workers and MPWG workers respectively.

Table III Correlation coefficient ( $r$ ) between Fat index (FI) and other parameters, viz systolic Blood pressure (SBP), diastolic Blood pressure (DBP), pulse rate (PR), Body Mass Index (BMI), Maximum Abdominal circumference (MAbc) for both group of workers.

\begin{tabular}{|c|c|c|}
\hline Correlation of & LPWG workers & MPWG workers \\
\hline FI-SBP & 0.524 & 0.128 \\
\hline FI-DBP & 0.2406 & 0.295 \\
\hline FI-PR & -0.1124 & 0.348 \\
\hline FI- BMI & 0.169 & 0.239 \\
\hline FI- MAbc & 0.221 & -0.12 \\
\hline
\end{tabular}

From the study of the musculoskeletal disorder (MSD) of the workers (Table-IV) it has been revealed that the percentage of occurrence of musculoskeletal disorder (MSD) in LPWG and MPWG workers has been presented in Figure 2. The result indicates that the MPWG workers suffers significantly $(p<0.001)$ higher percentage of MSD in the segment of neck, shoulder, elbow joint, wrist joint, finger, cuff muscle and feet-ankle region than that of the LPWG workers. But the LPWG workers suffer from significantly higher $(p<0.001)$ percentage of hip regional disorder than the MPWG workers. The percentages of lower back disorders are high in both groups of workers but also the MPWG suffer significantly $(p<0.05)$ higher lower back disorder than that of LPWG workers. 
Fig 2. Percentage of LPWG and MPWG workers reported musculoskeletal disorder (MSD) in different parts of the body during performing their task.

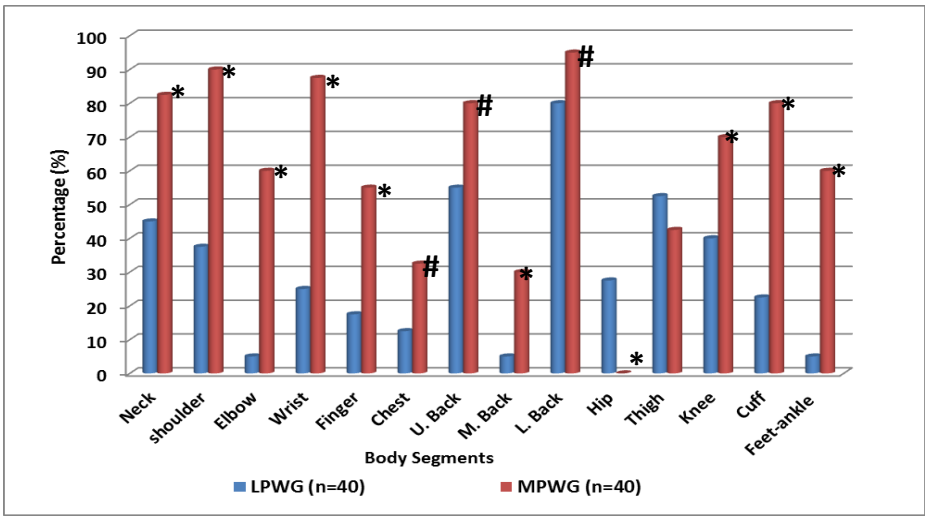

It was noted form the results that the average blood hemoglobin values of both group of workers were below the normal range (Table IV). Especially, the value for the MPWG workers was very low and also significantly $(p<0.01)$ differ from the LPWG workers.

Table IV Hemoglobin concentration of LPWG and MPWG workers.



Pregnancy and menstrual cycle related problems are tabulated in Table $\mathrm{V}$, which indicates that negligible problems they had to face during these two physiological aspects.

Table I Percentage of problem during Menstrual cycle and Pregnancy.

\begin{tabular}{|c|c|c|}
\hline & LPWG workers & MPWG workers \\
\hline $\begin{array}{c}\text { Menstrual Cycle - } \\
\text { Regular } \\
\text { Irregular }\end{array}$ & $15 \%$ & $80 \%$ \\
\hline Problem during pregnancy & $45 \%$ & $20 \%$ \\
\hline Yes & & \\
No & $15 \%$ & $20 \%$ \\
\hline
\end{tabular}

\section{Discussion}

The result of the present study indicate that all the parameters, viz., height, weight, BMI, BSA, mean abdominal circumference (Mabc), fat \% and fat index, all are significantly higher in LPWG. The similar trend was observed in case of the cardiovascular parameters. These higher values may be due to higher calorie consumption in sedentary worker because of their financial status. From our previous study [23] it has been revealed that the
Fat\% and other body composition increase with increase of nutritious food intake, which is indirectly correlated with family income. From The study of the other scientist [24, 25] it has been revealed that the monthly family income significantly and positively correlated with BMI. Body mass index (BMI) is widely accepted as one of the best indicators of nutritional status in adults [26, 27, 28, 29] BMI alone is sufficient to define chronic energy deficiency (CED) in adults.[26] On the basis of the CED classification [26] according to BMI the LPWG workers $(B M I=$ 24.32) belong to normal category (BMI range >20.0 - 25.0), whereas the MPWG workers $(\mathrm{BMI}=19.55)$ belong to low weight normal (BMI range $>18.5$ to 20.0). From the study of the $\mathrm{BMI}$ and body fat content of the MPWG workers, it was revealed that the workers suffered from lower degree of nutritional deficiency. The nutritional deficiency also plays role on the cardiovascular system. From the result it has been revealed that the percentage of hypotensive blood pressure of the MPWG workers was comparatively high than that of the other group. The regular physical activities as well as low diet might be the reasons for having hypotensive blood pressure in the workers. The socioeconomic status and body composition was an important factor for high blood pressure and aging.[30] Obesity is a significant problem in many developing countries, and it is associated with a high prevalence of hypertension, particularly in women.[31] There are also a positive correlation was found between FI and SBP for LPWG workers. The food habit also reflects the hemoglobin concentration of the body. The results indicates that the MPWG workers has the very low hemoglobin concentration and significantly $(p<0.01)$ differ than that of the other group. These low values might be related to the poor nutritional status of the workers and also due to consumption of low iron containing food. Several studies have shown that iron deficiency anemia (IDA) still continuous to be wide spread in all communities [32]. The MPWG workers were needed to improve their consumption of protective foods such as green leafy vegetables; other vegetables etc. By providing some educational program on the basis of nutrition which could help them to understand the food value of the nutritious food and to know the food group containing high iron which are easy available.

From the study of the MSD it has been revealed that the MPWG workers suffers from much more MSD than that of the LPWG workers. According to Guo et al education level also had a significant association with MSD.[33] In the present study it has been observed that the MPWG workers had low socio-economic condition. It might be one of the reasons for high occurrence of MSD. 


\section{Conclusion}

From the overall discussion it may be concluded that the present study may be helpful for evaluating the health status of women having different work pattern. Furthermore, the risk factor for the occurrence of different cardiovascular abnormalities could be identified and accordingly prevention program, regarding proper food habit be undertaken. It may be pointed out that, some further study is required to evaluate an overall picture regarding the health status of the women. A study for assessing the nutritional status is very much essential.

\section{References}

1. Park JE, Park K. Test book of preventive and social medicine. Banarsida Bhanot, $12^{\text {th }}$ ed.1989.p.8-372.

2. WHO Collaborating Centres in Occupational Health, Global Strategy on Occupational Health for All: The Way to Health at Work, World Health Organization, Geneva, Switzerland, 1994.

3. Saiyed HN, Tiwari RR. Occupational health research in India. Industrial Health. 2004, 42(2): 141-148.

4. Pereira MA, Kriska AM, Collins VR. Occupational status and cardiovascular disease risk factors in the rapidly developing, high-risk population of Mauritius. American Journal of Epidemiology. 1998, 148(2) : 148-163.

5. Mazloum A, Nozad H, Kumashiro M. Occupational low back pain among workers in some small-sized factories in Ardabil, Iran. Industrial Health. 2006, 44(1): 135-139.

6. Eriksen W, Natvig B, Bruusgaard D. Smoking, heavy physical work and low back pain: a four-year prospective study. Occupational Medicine.1999, 49(3): 155-160.

7. Barreto SM, Swerdlow AJ, Smith PG, Higgins CD. A nested case-control study of fatal work related injuries among Brazilian steel workers. Occupational and Environmental Medicine.1997, 54(8): 599-604.

8. Saha TK, Dasgupta A, Butt A, Chattopadhyay O. Health status of workers engaged in the small-scale garment industry: how healthy are they. Indian Journal of Community Medicine. 2010, 35(1):179-182.

9. Cosenzi AA, Piemontesi F, Virg - ili, Sacendote A, Franco G, Bellini G. A comparative study of blood pressure and body composition in body builders and obese subject, G. Clin Med. 1990, 71(8): 499-504.

10. Richard N Re. Obesity-Related Hypertension. Ochsner J. 2009, 9(3): 133-136.

11. Ballew C, Kiang L, Peter S, Albert O, Carey S. The utility of indirect measures of obesity in racial comparisons of blood pressure. J clin Epidemol. 1990, 43(8): 799-804.

12. Ermakova SV, Podstavkina TP, Strokina AN. Anthropometric Atlas, Recommendation of methods. Amerind publishing Co.Pvt. Ltd., New Delhi. 1985.

13. Weiner JS, Lourie JA. Human biology, A guide to field method. Black well scientific publications, Oxford. 1969.
14. Johnson BL, Nelson JK. Practical measurement for evaluation in physical education. Macmillion publishing Company, New York. 1986: 174-200.

15. Shaver L. Essential of exercise physiology, Surjeet Publication, Delhi. 1982.

16. Jackson AS, Pollock ML. Generalized Equations for predicting body density of men. British Journal of Nutrition. 1978, 40: 497504.

17. Jackson AS, Pollock ML, Ward A. Generalized equations for predicting body density of women. Medicine and Science in Sports and Exercise. 1980, 12: 175-182.

18. Siri WE. Gross composition of the body. In : Advances in Biological and Medical Physics, J. H. Lawrence and C. A. Tobias (eds.), Academic press, New York. 1956.

19. Kuorinka I, Jonson B, Kilbom A, Vinterberg $H$, BieringSorenson F, Anderson G, Jorgensen K. Standardized Nordic questionnaire for the analysis of musculoskeletal symptoms. Applied Ergonomics. 1987, 18: 233-237.

20. Ghai CL. A test book of Practical Physiology. $6^{\text {th }}$ ed. Jaypee brothers medical Publishers (P) Itd., New Delhi, 2005 : 29-33

21. WHO. Expert committee report on hypertension. Technical Report Series, No. 628. 1978.

22. JNC-VI. The sixth report of the Joint National Committee on Prevention, Detection, Evaluation and Treatment of High blood pressure. NIH Publication No. 98-4080. 1997.

23. Arora D, Ahmed QZ, Sau SK, Dekate R, Dutta S. Comparative Evaluation of Health Status of Bengali Women Depending on Socioeconomic Status. Natio. Jour of Med. and Alli. Scs. 2012, 1(2): $19-30$

24. Bose K, Bisai S, Das P, Dikshit S, Pradhan S. Interrelationships of income, chronic energy deficiency, morbidity and hospitalization among adult male slum dwellers of Midnapore, west Bengal, India. Journal of Biosocial Science. Cambridge University Press. 2006.

25. Chakraborty K, Bose K, Bisai S. Body Mass Index and Chronic Energy Deficiency among urban Bengalee Male slum Dwellers of Kolkata, India : Relationship with family income. Int. Jour. of Anthropology.2007, 21(3-4): 209-215.

26. Ferro-Luzzi A, Sette S, Franklin M, James WP. A simplified approach of assessing adult chronic deficiency. Eur J Clin Nutr 1992, 46:173-86.

27. Shetty PS, James WP. Body mass index: A measure of chronic energy deficiency in adults. FAO Food Nutr Pap. 1994, 56:1-57.

28. Bailey KV, Ferro-Luzzi. Use of body mass index of adults in assessing individual and community nutritional status. Bull WHO. 2005, 73: 673-680.

29. Lee RD, Nieman DC. Nutritional assessment. New York: McGraw Hill, 2003.

30. Rooks RN, Simonsick EM, Miles T, Newman A, Kritchevsky SB, Schulz $R$, et al. The association of race and socioeconomic status with cardiovascular disease indicators among older adults in the health, aging, and body composition study. J Gerontol B Psychol Sci Soc Sci. 2002 Jul, 57(4): S247-56.

31. Forrester $T$, Wilks $R$, Bennett $F$, McFarlane-Anderson $N$, McGee D, Cooper R, et al. Obesity in the Caribbean. Ciba Found Symp. 1996, 201:17-31.

32. National Nutrition Monitoring Bureau : Prevalence of Micronutrient Deficiencies. NNMB Technical Report No. 22 National Institute of Nutrition ICMR Hyderabad, 2003.

33. Guo HR, Chang YC, Yeh WY, Chen CW, Guo YL. Prevalence of musculoskeletal disorder among workers in Taiwan: A nationwide study. Journal of Occupational Health. 2004, 46(1):2636 